\title{
Effect of fly ash on the structure and strength of concrete
}

\author{
Jun Liu ${ }^{1,2}$ a , Yahui Zhang ${ }^{1, b}$,Runqing Liu ${ }^{2, \mathrm{c}}$ and Chao Duan ${ }^{1, \mathrm{~d}}$ \\ ${ }^{1}$ College of materials science and engineering Shenyang Jianzhu University, Shenyang, China \\ ${ }^{2}$ College of materials science and engineering Shenyang Ligong University, Shenyang, China

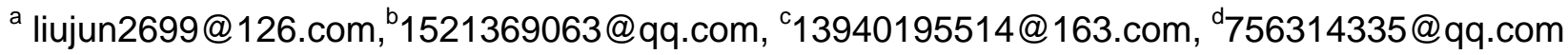

Keywords: concrete; fly ash; comprehensive strength; fractal dimension

Abstract. In order to explore the effect of fly ash on the pore structure and comprehensive strength properties of concrete, the effect of contents and particle size distribution of fly ash on the grade pore porosity and strength of the concrete were analyzed by mercury intrusion method. The results show that, decreasing the particle size of the fly ash leads to decrease of the porosity and less of the more harmful hole and harmful hole, while the harmless hole and the less harmful hole gradually increase. In addition, through the calculation on the fractal dimension of concrete grade pore porosity, it is found that there is a good correlation between the fractal dimension and strength of the concrete.

\section{Introduction}

Fly ash as a kind of mineral admixture with excellent performance, has three major effects[1], the performance of concrete can be improved with its incorporation. Fine particle size of fly ash has a good chemical activity, and it can well fill the gap between the cement particles, forming a good secondary particle gradation with unhydrated cement particles, and thus improving the pore structure and compressive strength of concrete. Based on the foundation, the effect of fly ash content and particle size distribution on pore structure and strength of concrete, which is of great significance to the change of macroscopic performance of concrete was investigated [2-6].

It is illustrated that the pore structure inside the concrete is very complicated and disorderly distributed by scanning electron microscopy[7], and it is far from the characteristics of traditional assumption that the structure of the pore is straight, and equal size, and smooth [8].So the traditional method can not be an effective quantitative description of its complexity. Fractal geometry[9] is a new branch of mathematics which developed by Mandelbrot, as an important parameter in the discipline, fractal dimension can be quantitatively described the complexity of geometries. Concrete, whether in its formation or in the course of work have shown a series of fractal characteristics[10-12]. During the study of concrete, the strength is closely related to the porosity and pore size distribution, therefore, in this paper, on the basis of studying the fractal dimension of each pore in concrete, the relationship between compressive strength and fractal dimension of concrete grade pore porosity were discussed.

\section{Materials and methods}

Materials .42 .5 ordinary Portland cement with specific surface area of $380 \mathrm{~m}^{2} / \mathrm{kg}$ was supplied by Shenyang Jidong cement factory. Crushed stone as a kind of coarse aggregate with particle size ranges from 5 to $20 \mathrm{~mm}$ and a maximum particle size of $20 \mathrm{~mm}$ was used in this experiment. River sand (fine aggregate) with fineness modulus of 2.8 was also used here. Naphthalene superplasticizer with water reducing rate of $18 \%-25 \%$ was used in this experiment. I grade fly ash is produced by Shenyang Shenhai thermal power plant and the loss on ignition is $1.29 \%$. Its main chemical composition is shown in Table 1.

Table 1 Chemical composition of fly ash

\begin{tabular}{llllllll}
\hline $\mathrm{SiO}_{2}$ & $\mathrm{Al}_{2} \mathrm{O}_{3}$ & $\mathrm{Fe}_{2} \mathrm{O}_{3}$ & $\mathrm{CaO}$ & $\mathrm{MgO}$ & $\mathrm{Na}_{2} \mathrm{O}$ & $\mathrm{K}_{2} \mathrm{O}$ & others \\
\hline 59.95 & 26.78 & 4.35 & 2.30 & 1.53 & 1.25 & 2.75 & 1.29 \\
\hline
\end{tabular}




\section{Methods.}

Preparation of fly ash. The fly ash with different particle sizes was prepared by changing the milling time, of which the grinding time for $0 \mathrm{~min}$ is termed as F0 and grinding for $60 \mathrm{~min}$ as F1, grinding for $90 \mathrm{~min}$ as F2.After that, the particle size range was tested by laser particle size analyzer, and the results were shown in Table 2.

Table 2 Particle size distribution of the fly ash

\begin{tabular}{|c|c|c|c|c|c|c|}
\hline Number & $\begin{array}{c}\text { Average particle } \\
\text { size of surface } \\
\text { area } \\
/ \mu \mathrm{m}\end{array}$ & $\begin{array}{c}\text { Average } \\
\text { particle size } \\
\text { of volume } \\
\quad / \mu \mathrm{m}\end{array}$ & 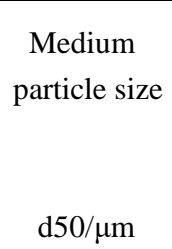 & $\mathrm{d} 10 / \mu \mathrm{m}$ & $\mathrm{d} 50 / \mu \mathrm{m}$ & $\begin{array}{c}\text { Distribution } \\
\text { width } \\
\text { S }\end{array}$ \\
\hline F0 & 7.63 & 38.20 & 19.82 & 3.22 & 97.73 & 24.20 \\
\hline $\mathrm{F} 1$ & 6.60 & 29.40 & 16.41 & 2.83 & 67.82 & 17.17 \\
\hline F2 & 5.93 & 20.46 & 13.13 & 2.55 & 47.81 & 13.60 \\
\hline
\end{tabular}

Mix ratio of concrete.Adopted standard curing regime $\left(20^{\circ} \mathrm{C}\right)$, the size of concrete specimen is $100 \mathrm{~mm} \times 100 \mathrm{~mm} \times 100 \mathrm{~mm}$, consistent water to binder ratio is 0.42 , the amount of cement, replaced by fly ash, was $15 \%, 16 \%, 17 \%, 18 \%, 19 \%$ and $20 \%$, respectively. The experimental mix ratio of cement paste design is shown in Table3.

\begin{tabular}{cccccccc}
\multicolumn{7}{c}{ Table3 Mix ratio of concrete $(\mathrm{kg} / \mathrm{m} 3)$} \\
\hline Number & Cement & Fly ash & Replacement rate & Water & Sand & Stone & Water reducer \\
& & & & & & \\
\hline A & 410 & 0 & $0 \%$ & 172 & 545.4 & 1272.6 & 4.1 \\
B & 348.5 & 61.5 & $15 \%$ & 172 & 545.4 & 1272.6 & 4.1 \\
C & 344.4 & 65.6 & $16 \%$ & 172 & 545.4 & 1272.6 & 4.1 \\
D & 340.3 & 69.7 & $17 \%$ & 172 & 545.4 & 1272.6 & 4.1 \\
E & 336.2 & 73.8 & $18 \%$ & 172 & 545.4 & 1272.6 & 4.1 \\
F & 332.1 & 77.9 & $19 \%$ & 172 & 545.4 & 1272.6 & 4.1 \\
G & 328.0 & 82.0 & $20 \%$ & 172 & 545.4 & 1272.6 & 4.1 \\
\hline
\end{tabular}

Preparation of the specimens for mercury intrusion porosimetry (MIP) test.The interior part of the specimens curing for 7days was immersed in absolute ethanol for $48 \mathrm{~h}$ to terminate the hydration. After that it was placed in the oven for $24 \mathrm{~h}$ at the temperature of $105^{\circ} \mathrm{C}$, which was prepared for the MIP[13].

\section{Results and discussions}

Effects of fly ash content on strength of concrete at different curing ages. Taking concrete with fly ash particle size F0 as an example, in order to explore the influence of fly ash content on compressive strength of concrete at different curing ages, set the control group that the replacement rate of fly ash is $0 \%$, test group fly ash replacement rate changes from $15 \%$ to $20 \%$, (gradient gap is $1 \%$ ), the compressive strength test results of concrete at $3 \mathrm{~d}, 7 \mathrm{~d}$ and $28 \mathrm{~d}$ are shown in Table 4 , the relationship between the dosage and the strength is shown in Fig.1. 
Table 4 Compressive strength of concrete with fly ash particle size F0

\begin{tabular}{cccc}
\hline \multirow{2}{*}{ Content $(\%)$} & \multicolumn{3}{c}{ Compressive strength(Mpa) } \\
\cline { 2 - 4 } & $3 \mathrm{~d}$ & $7 \mathrm{~d}$ & $28 \mathrm{~d}$ \\
\hline $0 \%$ & 30.4 & 35.6 & 44.5 \\
$15 \%$ & 25.2 & 31.9 & 43.0 \\
$16 \%$ & 24.2 & 31.6 & 43.3 \\
$17 \%$ & 24.4 & 30.2 & 41.0 \\
$18 \%$ & 22.7 & 31.2 & 40.6 \\
$19 \%$ & 21.3 & 30.8 & 40.0 \\
$20 \%$ & 19.1 & 28.6 & 38.5 \\
\hline
\end{tabular}

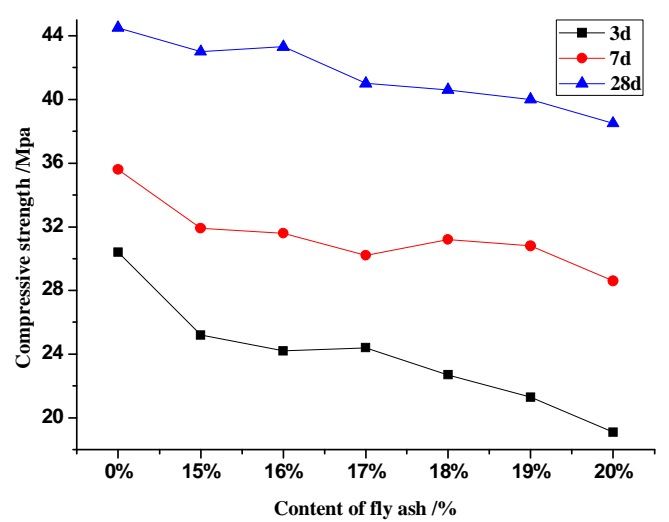

Fig.1 Relationship between fly ash content and compressive strength of concrete at different ages

As can be seen from Fig.1, the early strength of concrete decreases with the incorporation of fly ash. Compared with the control group, the average compressive strength of concrete with $15 \%$ replacement of fly ash at $3 \mathrm{~d}$ and $7 \mathrm{~d}$ decreased by $5.2 \mathrm{MPa}$ and $3.7 \mathrm{MPa}$, percentages of strength decreased by $17.1 \%$ and $10.4 \%$, it can be seen that the addition of fly ash has a certain weaken effect on the early compressive strength of concrete, this is because the early strength of concrete mainly from cement hydration, when fly ash replace cement at the same quality it will lead to a reduction in the quality of the cement that can be hydrated, and the compressive strength of the concrete is reduced[14], no matter what kind of curing age, it can be clearly seen that in the test group, the compressive strength of concrete with $15 \%$ fly ash content is larger, and the content of $20 \%$ of the concrete compressive strength is relatively small.

Effects of particle size distribution of fly ash on compressive strength of concrete at different ages.In the test group, when the content of fly ash is $15 \%$, the compressive strength of concrete is relatively good, and it has a good representation, which can better highlight the effect of fly ash particle size distribution on compressive strength, when exploring the relationship between the particle size distribution of fly ash and the compressive strength of concrete, select the three kinds of concrete which particle size of fly ash is F0, F1, F2, and the content is $15 \%$. Test the compressive strength of concrete at age $3 \mathrm{~d}, 7 \mathrm{~d}$ and $28 \mathrm{~d}$, the fly ash concrete with particle size F0 is the control group and test results are shown in Fig.2. 


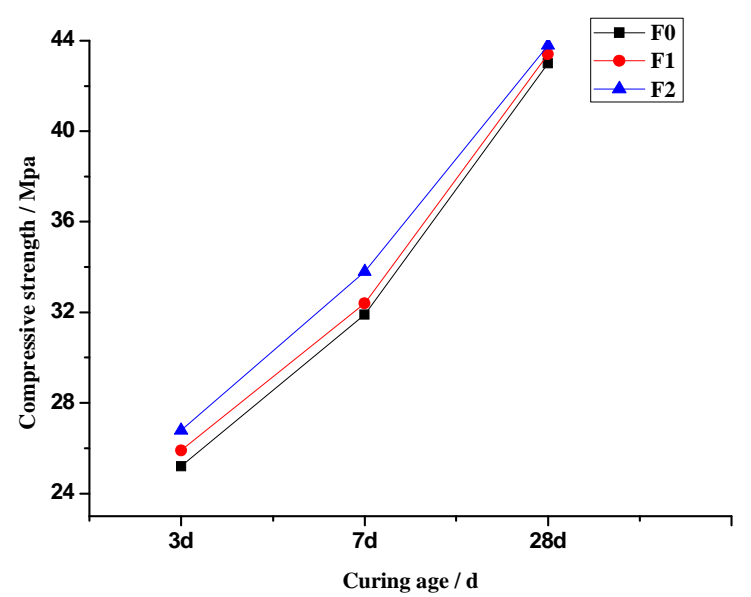

Fig.2 Relationship between particle size of different fly ash and compressive strength of concrete

As an be seen from Fig.2, with the extension of the curing age the compressive strength of concrete gradually increased, the compressive strength of the test group concrete with smaller particle size fly ash was higher than that of the control group in the early stage ( $3 \mathrm{~d} \sim 7 \mathrm{~d})$, and the compressive strength between the two is very close to that in the later stage of conservation $(28 \mathrm{~d})$. When the curing age is 7 days, the compressive strength of the concrete corresponding to the fly ash with the particle size of F2 compared to the particle size of F0, F1 fly ash corresponding to the compressive strength of concrete were increased 1.9MPa, 1.4MPa, strength growth rate respectively of $5.9 \%$ and $4.3 \%$. When the curing age reached 28 days, the compressive strength of the concrete corresponding to the fly ash with the particle size of F2 compared to the particle size of F0, F1 fly ash corresponding to the compressive strength of concrete were increased $0.8 \mathrm{MPa}, 0.4 \mathrm{MPa}$, strength growth rate respectively of $1.8 \%$ and $0.9 \%$.

Effects of fly ash on porosity of concrete pore.In order to further explore the effect of different fly ash content and particle size distribution on the pore structure of concrete, in this paper, the porosity characteristics of concrete which curing 7 days that the particle size of fly ash is F0, F1, F2, and content are $15 \%, 16 \%, 17 \%, 18 \%, 19 \%, 20 \%$ were analyzed by mercury intrusion test. The results are shown in Table 5,the relationship between the changes shown in Figs.3.

\begin{tabular}{|c|c|c|c|c|c|}
\hline \multirow[t]{5}{*}{ Particle size } & \multirow{2}{*}{$\begin{array}{c}\text { Content } \\
(\%)\end{array}$} & \multicolumn{4}{|c|}{ Porosity of each pore size } \\
\hline & & $>200 \mathrm{~nm}$ & $50-200 \mathrm{~nm}$ & $20-50 \mathrm{~nm}$ & $<20 \mathrm{~nm}$ \\
\hline & 15 & 1.816 & 1.921 & 4.718 & 7.069 \\
\hline & 16 & 2.858 & 1.986 & 4.902 & 8.308 \\
\hline & 17 & 2.963 & 2.053 & 5.376 & 9.161 \\
\hline \multirow[t]{6}{*}{ F0 } & 18 & 2.946 & 2.597 & 5.903 & 9.391 \\
\hline & 19 & 3.701 & 2.721 & 6.843 & 9.865 \\
\hline & 20 & 3.898 & 2.976 & 8.637 & 10.432 \\
\hline & 15 & 1.775 & 1.607 & 2.065 & 7.911 \\
\hline & 16 & 1.813 & 1.653 & 2.569 & 7.923 \\
\hline & 17 & 1.907 & 1.743 & 2.761 & 8.332 \\
\hline \multirow[t]{6}{*}{$\mathrm{F} 1$} & 18 & 1.944 & 1.893 & 3.586 & 9.173 \\
\hline & 19 & 2.383 & 1.986 & 3.733 & 9.322 \\
\hline & 20 & 2.949 & 2.036 & 4.535 & 9.807 \\
\hline & 15 & 1.009 & 1.137 & 1.468 & 8.865 \\
\hline & 16 & 1.838 & 1.258 & 1.479 & 9.462 \\
\hline & 17 & 1.858 & 1.353 & 2.403 & 9.764 \\
\hline \multirow[t]{3}{*}{ F2 } & 18 & 1.936 & 1.415 & 2.862 & 9.931 \\
\hline & 19 & 1.996 & 1.689 & 2.939 & 9.985 \\
\hline & 20 & 1.997 & 1.881 & 3.894 & 10.442 \\
\hline
\end{tabular}




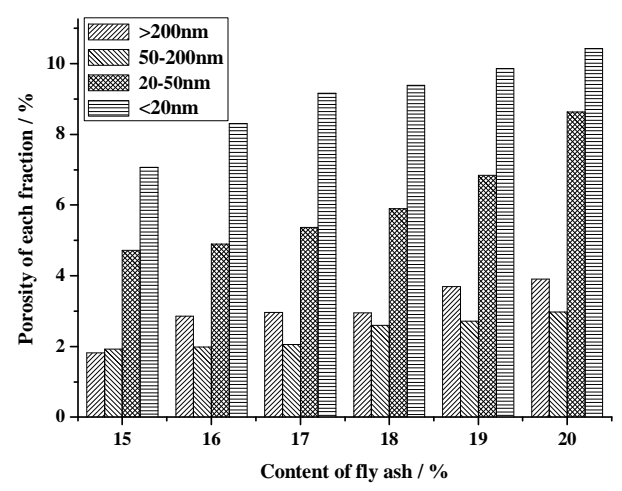

(a) The relationship between F0 fly ash content and porosity of each pore size

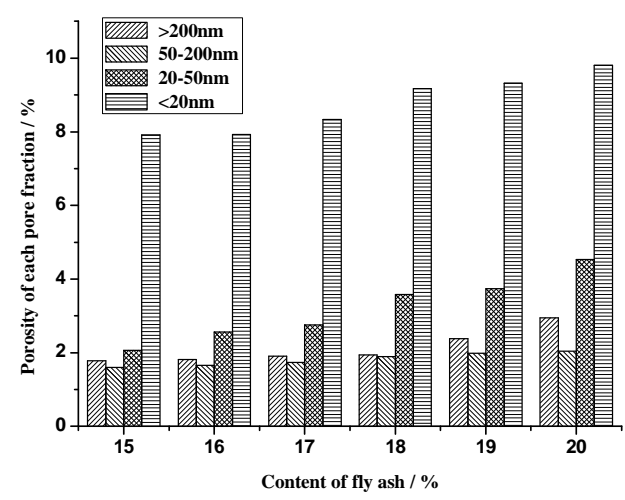

(b) The relationship between F1 fly ash content and porosity of each pore size

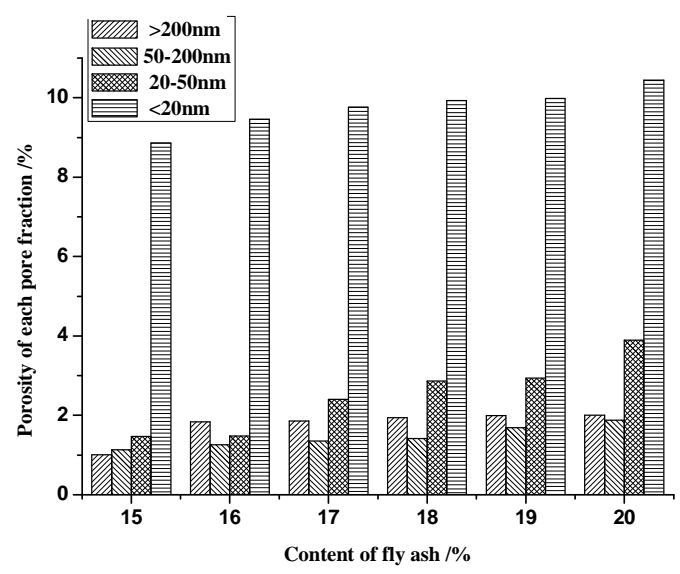

(c) The relationship between F2 fly ash content and porosity of each pore size

Figs.3 Porosity of concrete with different particle size and different content of fly ash

As can be seen from Table 4 and Figs. 3 that when the fly ash content is the same, with reduction of particle size of fly ash(the longer the grinding time) the graded porosity of less harmful hole, more harmful hole and harmful hole decreased, while the harmless hole and less harmful hole (>50nm) increased to make the pore size distribution well optimized. When the particle size of fly ash is same, the graded porosity of less harmful hole, more harmful hole and harmful hole increased. This is due to the combined effect of the following two factors: (1) As the fly ash particle size changes its micro-aggregate effect and volcanic ash effect is more significant,as the fly ash particle size changes its micro-aggregate effect and volcanic ash effect is more significant, after incorporation it full with cement hydration products $\mathrm{Ca}(\mathrm{OH})_{2}$ occur secondary hydration reaction and the products can better filling the pores, so that the concrete pore refinement, porosity reduction, and density of concrete has been greatly improved.(2) Fly ash instead of cement make the amount of cement reduce, and at the same time due to low activity of fly ash, and its secondary hydration reaction is slow, especially in the case of higher fly ash content, which will lead the porosity of concrete increased .

\section{Effects of different particle size distribution and different content of fly ash on the fractal}

dimensions of the pores of concrete.The calculation results of different fly ash content and particle size distribution on fractal dimension of concrete pore are shown in Table 6 , and the relationship is shown in Fig.4.

Table 6 Different content and particle size distribution of fly ash and the fractal dimension of concrete pore

\begin{tabular}{cccc}
\hline Content $(\%)$ & Fractal dimension of F0 & Fractal dimension of F1 & Fractal dimension of F2 \\
\hline 15 & 2.78306 & 2.84156 & 2.88932 \\
16 & 2.74552 & 2.8109 & 2.8624 \\
17 & 2.73691 & 2.79817 & 2.8501 \\
18 & 2.73445 & 2.78665 & 2.82498 \\
19 & 2.70896 & 2.7862 & 2.81748 \\
20 & 2.68987 & 2.76724 & 2.81392 \\
\hline
\end{tabular}




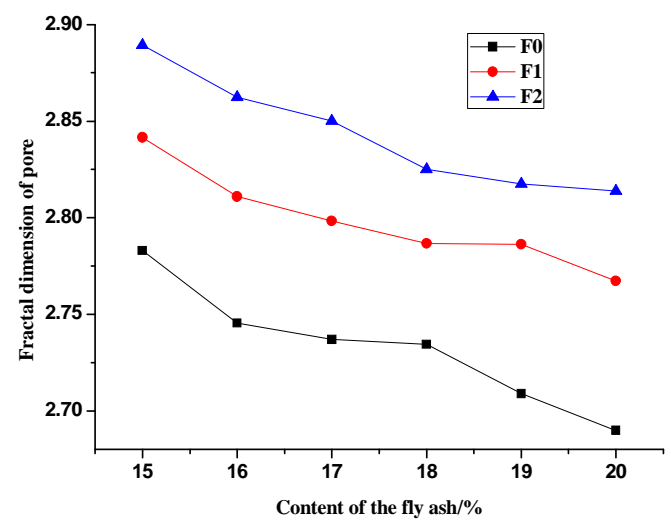

Fig.4 The relationship between different content and particle size distribution of fly ash and fractal dimension of concrete pore

It can be seen from Fig.4 that when the particle size of fly ash is the same, the fractal dimension of concrete decreases with the increasing of fly ash content, when the content of fly ash is $20 \%$ the fractal dimension of concrete is the smallest. This is because fly ash replacing cement make the amount of cement reduce, and due to the low activity and low secondary hydration reaction of fly ash, especially in the case of higher fly ash content, which will lead the porosity of concrete increased. When the content of fly ash is constant, the fractal dimension of the concrete increases with the decrease of the particle size of the fly ash. This is owing to the reduction of fly ash particle size which make fly ash have a better filling effect that can form a good gradation with the cementitious material, while due to the reduction of particle size, its specific surface area and chemical activity increased which enhance the secondary hydration reaction rate, so more hydration products generate in the unit time that can refinement of the pore size, which makes the porosity of the concrete reduced and the fractal dimension of the pore increased.

Effect of fractal dimension of concrete pore on compressive strength.Numerous studies proved that[15-17], the compressive strength of concrete is not only related to pore size, and porosity has a decisive effect on the strength of concrete, and at the same time, the fractal dimension of pore also has an effect on the strength of concrete. The compressive strength and pore fractal dimension of concrete are shown in Table 7, and the relationship is shown in Fig.5.

Table 7 The compressive strength and pore fractal dimension of concrete

\begin{tabular}{cccccc}
\hline & F0 & \multicolumn{2}{c}{ F1 } & F2 \\
\hline $\begin{array}{c}\text { compressive } \\
\text { strength } \\
(\mathrm{Mpa})\end{array}$ & $\begin{array}{c}\text { Fractal dimension of } \\
\text { porosity }\end{array}$ & $\begin{array}{c}\text { compressive } \\
\text { strength } \\
\text { (Mpa) }\end{array}$ & $\begin{array}{c}\text { Fractal dimension of } \\
\text { porosity }\end{array}$ & $\begin{array}{c}\text { compressive } \\
\text { strength }\end{array}$ & $\begin{array}{c}\text { Fractal dimension of } \\
\text { porosity }\end{array}$ \\
\hline 31.9 & $\mathrm{D}$ & 32.4 & $\mathrm{D}$ & (Mpa) & D \\
31.6 & 2.78306 & 32.9 & 2.84156 & 33.8 & 2.88932 \\
30.2 & 2.74552 & 31.7 & 2.7109 & 34.2 & 2.8624 \\
31.2 & 2.73691 & 31.4 & 2.78665 & 31.7 & 2.8501 \\
30.8 & 2.73445 & 31.7 & 2.7862 & 32.2 & 2.82498 \\
28.6 & 2.70896 & 30.4 & 2.76724 & 31.6 & 2.81748 \\
\hline
\end{tabular}




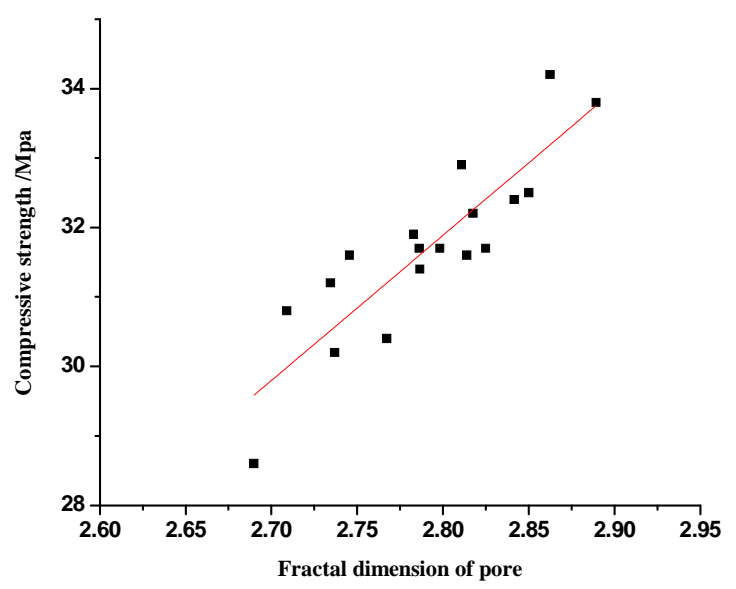

Fig.5The relationship between compressive strength of concrete and fractal dimension of porosity

It can be seen from Table 7and Fig. 5 that the greater the compressive strength of concrete is, the fractal dimension of pore its correspondence is more large, there was a positive correlation between compressive strength and pore fractal dimension. This is because when the range of pore is constant, the fractal dimension decreases as the porosity increases. When the porosity is constant, the fractal dimension is determined by the range of pore, the narrower the range of pore distribution, the smaller the fractal dimension is, for the reason that the porosity is the main factor to determine the strength of concrete, the smaller the porosity is, the larger the fractal dimension of the pore and compressive strength of the concrete are.

\section{Conclusions}

(1) The addition of fly ash has a certain weaken effect on the early compressive strength of concrete, the compressive strength of concrete with $15 \%$ fly ash content is larger, and the content of $20 \%$ of the concrete compressive strength is relatively small.

(2) With the extension of the curing age the compressive strength of concrete gradually increased, the compressive strength of the test group concrete with smaller particle size fly ash was higher than that of the control group in the early stage ( $3 \mathrm{~d} \sim 7 \mathrm{~d}$ ), and the compressive strength between the two is very close to that in the later stage of conservation $(28 \mathrm{~d})$.

(3) When the fly ash content is the same, with reduction of particle size of fly ash(the longer the grinding time) the graded porosity of less harmful hole, more harmful hole and harmful hole decreased, while the harmless hole and less harmful hole $(>50 \mathrm{~nm})$ increased to make the pore size distribution well optimized. When the particle size of fly ash is same, the graded porosity of less harmful hole, more harmful hole and harmful hole increased.

(4) When the particle size of fly ash is same, the fractal dimension of concrete decreases with the increasing of fly ash content, the content of fly ash is $20 \%$ the fractal dimension of concrete is the smallest. When the content of fly ash is constant, the fractal dimension of the concrete increases with the decreasing of the particle size of the fly ash. The greater the compressive strength of concrete is, the fractal dimension of pore its correspondence is more large, there was a positive correlation between compressive strength and pore fractal dimension.

\section{Acknowledgements}

The author would like to express the appreciation for the financial support by Liaoning Provincial Higher Education Innovation Team Project(LT2015024 ). 


\section{References}

[1] Li xia ZHOU, Qi cai WANG. Journal of building materials [J]. The relationship between particle fineness and performance of fly ash cement mortar .2007: 5-6.

[2] ASTM Designation : C 671 -94,Standard test method for critical di-ation of concrete specimens subjected to freezing.

[3] Vesa Penttala , Fahim Al - Neshawy. Stress and state of concrete during freezing and thawing cycles[J].Cement and Concrete research.2002,32:1407 -1420.

[4] P. Goltermann . Mechanical predictions of concrete deterioration. Eigenstresses in concrete[J].Am Concr Inst Mater J 91, 1994: 543.

[5] E.J. Garboczi . Stress. Displacement and expansive cracking around a single spherical aggregate under different expansive conditions [J]. Cement and concrete research.1997, 27: 495- 501.

[6] R.Piltner. On the fepresentation of three- dimensional elasticity solutions with the aid of complex valued functions [J].J Elasticity.1989, 22:45- 55

[7] Ming Tang, Xiao Li. Study on the influence of various factors on the fractal characteristics of concrete pore structure [J]. Journal of Shenyang Jianzhu university: Natural science edition.2005,21 (3): 232-237.

[8] Wei Guo, Hong gen Qin, Hui su Chen. Fractal theory and its application in the study of concrete materials [J]. Chinese journal of ceramics. 2010,38 (7): 1362-1368.

[9] Mandeibrot B B. The fractal geometry of nature [M] . New York: Freeman,1982: 1-17.

[10] Nai qian Feng. High performance concrete [M]. Beijing: China construction industry press.1996: 311-325.

[11] Chun XIA, Hao wu LIU. Study onfractal characteristics of concrete fine aggregate gradation [J]. Journal of southwestjiao tong university. 2002,37 (25): 186-189.

[12] Qian yuan Wang, Jing shuang Hu . Aggregate gradation and fractal of concrete [J]. Journal of Qingdao institute of civil engineering and architecture. 1997, (3): 93-99.

[13] ASTM Designation :C 671 -94, Standard test method for criticaldi-ation of concrete specimens subjected to freezing.

[14] Hong qi Li, Jian zhi Zheng. Effect of particle size and content of fly ash on strength of high performance concrete $[\mathrm{J}]$.North transportation.2015 (8): 22-25.

[15] Qing chao Meng. Study on the durability of concrete and the influencing factors of pore structure [D]. Harbin: Harbin Institute of technology degree thesis. 2006.

[16] Ming Tang, Zhe Chen, Fan Yang. Pore fractal and chloride ion permeation characteristics of C50 pumped concrete [J]. Journal of concrete. 2010, (4): 92-95.

[17] Shah S P, Wang K, Weiss J. Mixture proportioning for durable concrete [J]. Concrete Internationa.2000, (9): 73-78. 